\title{
Language Learning and Study Abroad: the European Perspective
}

\author{
J a m es A. Cole m a n \\ University of Portsmouth, United Kingdom
}

\section{Introduction}

The purpose of the present paper is to describe, for a North American audience, how "study abroad" or "residence abroad" is understood in the European context. Here, it is not merely an educational matter: the historical, geographical and political context of Europe has an important influence on the rationale for student residence abroad and on its organisation. As well as highlighting differences from the American context, the paper will describe features of current practice, focusing particularly on the United Kingdom, for several reasons. Residence abroad has been a compulsory part of most degrees in modern languages in the UK for many years, the UK has larger numbers of students involved in the process, and the evaluation of residence abroad has arguably been more systematic than elsewhere in Europe, where residence abroad is normally optional, is not closely integrated into the degree structure, and (at least until recently) has carried little or no weight within the credit structure of the degree. Finally, I shall review the published research into residence abroad, especially with regard to foreign language proficiency and to intercultural competence. The paper is divided into four sections dealing respectively with the European context, residence abroad in Europe, UKspecific information, and research findings.

\section{Note on terminology}

In common with some other articles on student residence abroad within Europe, which deal with many nationalities and a number of host 
countries, the present article refers to the target language as L2, the country or countries where it is spoken as L2land, and the inhabitants of those countries as L2landers. The students' mother tongue, home country and compatriots are correspondingly L1, L1land and L1landers.

\section{The political context and the role of European institutions}

An understanding of Europe depends on an appreciation of its history of internal conflict, and the density, within the European land mass, of different ethnic, religious, cultural and linguistic communities. War as we know it was invented in Europe. The expanding empires which competed over recent centuries to explore and to dominate the whole of the world had their base in Europe - in fact in just half a dozen western European states. In the present century, the two World Wars in which tens of millions died had their origins in Europe, in the same handful of states. Nor is it only in the past that Europe and conflict have been synonymous. In the 1990s, the bloody fighting in the former Yugoslavia, a conflict founded on ethnic, religious and linguistic as well as political differences, exploded a country with a population equal to that of California, but with only half the surface area. Understanding study abroad in the European context means first appreciating, on the one hand, the political will to tolerance and integration respecting cultural and linguistic diversity, and, on the other hand, the geographical and ethno-cultural scale involved.

Even before the economic dominance of the USA and the growth of Pacific rim economies, the devastating experience of two all-out wars persuaded European policymakers of the need to bring closer together the nations which gave birth to western civilisation, but which have more often been rivals than allies over two millennia. Two institutions in particular, the European Union and the Council of Europe, embody both the political will and the practical policies which are fundamental to student movement within Europe.

\section{The European Union}

The European Union (EU) is an economic and (in some senses) polit- 
ical union which began as the European Coal and Steel Community in 1952, became the European Economic Community (1958), then the European Community, and finally the European Union on 1 November 1993. It has expanded to a current membership of fifteen states: Austria, Belgium, Denmark, Finland, France, Germany, Greece, Ireland, Italy, Luxembourg, Netherlands, Portugal, Spain, Sweden, United Kingdom. It has an elected Parliament, a Council of Ministers made up of government Ministers from each of the member states, and a permanent Commission which implements policy.

Mobility is a central plank of EU policy: it refers to the free movement of citizens between EU member states, and is supported by a number of "actions," which seek in various ways to enhance mobility, for example by reducing border formalities, by outlawing national legislation which gives locals preferential access to jobs over nationals of other EU states, or by enhancing the learning of foreign languages, without which mobility of Europe's population cannot be a reality. At the same time, the EU seeks to maintain its cultural and linguistic diversity: multilingualism and multiculturalism are written into all its "actions."

EU cooperation in the field of education comes today under the SOCRATES programme, adopted in 1995. SOCRATES incorporates ERASMUS - originally the European Community Action Scheme for the Mobility of University Students - which was launched in 1987 and itself succeeded the Joint Study Programmes established in 1976. Under ERASMUS, grants are made for institutions to organise student and staff mobility, and for the mobility of individual students, very often in the form of exchanges. ERASMUS also covers related issues such as joint curriculum development, intensive language courses, and the European Credit Transfer Scheme, designed to ensure the academic recognition of studies undertaken abroad.

All these measures seek to advance European integration by promoting mobility among European citizens and by increasing cooperation and harmonisation among the universities of the member states. The ERASMUS programme is characterised by mobility only within Europe, for periods of up to one year, within networks of like-minded departments, embodying curricular integration and recognition, and a certain level of support activities such as preparation, help with accommodation, foreign language instruction, academic and administrative advice on 
arrival. Under SOCRATES, responsibility for all of an institution's networks has been transferred to a central European or international office. ERASMUS originally aimed to raise the percentage of students undertaking part of their degree programme in a different country from $4 \%$ to $10 \%$, i.e. some 150,000 students per annum, but funding was never sufficient to attain this target.

In 1987, 300 universities exchanged 3,000 students; in 1997, 1,500 universities exchanged 80,000 students: half a million students have now benefited from the programme, which probably embraces the majority of residence abroad students in Europe. The exchanges have also become more diversified geographically: in 1988/89, 62\% of student flows were within the "golden triangle," i.e., between Germany, France and the United Kingdom; by 1997/98, the figure was down to 49\%. It is claimed with some justice that ERASMUS has "made European cooperation between universities into the norm rather than the exception" (http://europa.eu.int/en/comm/dg22/socrates/erasmus/10ans-d.html).

Because there is unequal demand for European languages, with English the most popular, followed by French, German and Spanish, there is not always a balanced flow of students on ERASMUS programmes. Ireland, the UK, France and French-speaking Belgium are net recipients of ERASMUS students, other countries net exporters to different degrees, with Italy and Greece in greatest imbalance. Choice of destination is influenced by prior knowledge of $\mathrm{L} 2$ and a desire to improve proficiency in the L2 - this is indeed the prime reason for opting to study abroad (Opper, Teichler and Carlson, 1990; Teichler, 1997). The UK is consistently the largest recipient, although its overall share has reduced from about one-third to about one-quarter of all ERASMUS students. The UK, France and Germany are the largest exporters, each representing around one-sixth of total departures: the imbalance would be greater but for deliberate action on the part of the ERASMUS Bureau to enhance involvement of other countries. The demand to study in an English-speaking country has recently led a House of Lords Select Committee report (June 1998) to assert that the UK is a net importer of 45,000 European Union students, and that measures should be taken to persuade more British students to take part in SOCRATES-ERASMUS exchanges.

The sole language of instruction on $65 \%$ of programmes is the $\mathrm{L} 2$, with the remainder in visiting students' L1, a third language, or a mix- 
ture of languages. Thus $40 \%$ of all instruction is in English, 22\% in French, 16\% in German, 9\% in Spanish, 7\% in Italian, 6\% in other languages. The average of $79 \%$ of courses taught in the host university's native language conceals huge variation: 98\% are delivered in English in the UK and Ireland, and it is necessary to learn Portuguese, French, German, Italian or Spanish for sojourns where one of these is the L1. However, in countries whose native tongue is a LWULT (less widely used and less taught) language, such as Denmark or the Netherlands, much university teaching is delivered in English: thus, students with no Danish or Dutch may come to study, and allow Danish or Dutch students to go abroad. Less than 25\% of teaching is in the L1 in Denmark (19\%), Greece (22\%), and the Netherlands (23\%).

Within ERASMUS, students of Business Studies consistently represent $20 \%$ or above of participants, languages over $10 \%$, engineering, law and social science around $10 \%$ each. Students tend to come from bettereducated and better-off families: $46 \%$ estimated parental income as average and $41 \%$ as above-average (data from Teichler, 1997).

Evaluation of the success of EU exchange programmes, based on extensive report and questionnaire data, has been carried out on a continuing basis (see below).

\section{The Council of Europe}

The Council of Europe, based in Strasbourg, was established by ten states in 1949, in the wake of the Second World War, and now has forty members. Its role is to strengthen democracy, human rights and the rule of law throughout its member states, to enhance Europe's cultural heritage in all its diversity, and to act as a forum for examining a whole range of social problems. The Council of Europe is committed to diversifying and intensifying language learning in order to promote plurilingualism, mutual understanding and respect for cultural diversity in the European context. The Modern Languages Project Group of the Council for Cultural Co-operation, comprising experts on second language acquisition and pedagogy, has achieved much in the domain of language teaching and learning, including work on communicative methodology, learner autonomy, the definition of "Threshold Level" specifications, and improved teacher training. Most recently, it has published Modern Languages: 
Learning, Teaching, Assessment. A Common European Framework of Reference (Strasbourg, 1998) — a key document for all those involved with the learning of European languages.

Draft 1 of the Common Framework was published in 1996, and revised taking international feedback into account. The Framework emphasises the need to promote multilingual and multicultural education. The principal aim is to overcome linguistic barriers so as to:

I. increase personal mobility

II. increase the effectiveness of international cooperation

III. increase respect for cultural identity and diversity

IV. intensify personal interaction

V. improve working relations, and

VI. achieve a deeper mutual understanding

The Framework builds on the earlier, highly respected and influential Council of Europe language projects, in particular the work on Threshold levels which defined the objective of language learning in terms of real use, of enabling people to interact with one another. Related Council of Europe documents by Byram and Zarate (1997), Byram, Zarate and Neuner (1997), Holec (1994), Little (1994) and others on topics including intercultural competence, learner autonomy and learning strategies also fed into its preparation. Following the Council of Europe's definition of language as above all a social instrument, and other familiar definitions of communicative competence, the Framework views communicative competence (sociolinguistic, linguistic, pragmatic) as a form of general competence leading to language activity (interaction, production, reception, mediation) using tasks, texts and strategies in four principal domains (public, occupational, educational, personal) in which arise situations. Each situation consists of location, containing organisations which structure interaction, persons with specific roles, objects (animate and inanimate) which make up the environment, events which take place there, and operations which are performed. Despite the complexity which the need to be comprehensive imposes on the Framework, it is already achieving the status of a norm to which language curricula and tests should aspire. The Framework, together with a General Guide for Users and a series of Guides targeted at different sectors, is currently being further evaluated before a final revision expected in 2000 and Europe-wide adoption. All European work on issues related to language learning, 
including study or residence abroad, must henceforward take into account the Common European Framework.

\section{Scale, distance and difference}

Although the majority of borders within the European Union may now be crossed without any formalities whatsoever, the differences of scale between Europe and America need to be appreciated. A line from Glasgow, the largest city in north-west Europe, to Athens in south-eastern Europe crosses ten sovereign countries, but is shorter than the distance from San Francisco to Chicago. Language zones, cultural zones and even countries are relatively small. Thanks to a research link between Portsmouth and Duisburg, I regularly drive from the UK, through the tunnel into France, across the Flemish-speaking part of Belgium, through Holland, and into Germany, within a single working day. The European Union has eleven official languages, but an individual member state will also have other languages. Regional languages such as Welsh and Scots Gaelic in the United Kingdom, or Breton and Basque in France, have ethnic roots centuries old, and a culture distinct from the rest of the country. Additionally, there are the tongues and cultures brought by recent immigrants. It may seem surprising to non-Europeans that such a small area should encompass so many distinct linguistic and cultural communities, but it is a consequence of thousands of years of continuous migration, conquest and conflict, and must be recognised.

One consequence of the immense ethnic, linguistic and cultural diversity to be found within the relatively small area of Europe is that young Europeans - or at least those socio-economic groups from whom university students are drawn - have considerable experience of other lands. Language students have normally experienced cultural diversity before undertaking residence abroad as part of their university degree programme (Coleman, 1996a; Lillie, 1994; Meara, 1994; Swallow, 1986).

Coleman (1996a: 60-61, 190; 1998a: 48-9, 60-61) has shown that, by the second year of university study, i.e. before formal residence abroad which usually takes place during the third year, over $95 \%$ of UK language students ( $\mathrm{n}=4249)$ have already visited the L2land; in the case of students of French and German $(n=3447)$ the figure is above $99 \%$. Many have visited repeatedly and for long periods: $59.7 \%$ of students of French 
$(\mathrm{n}=2598)$ had visited a French-speaking country at least six times, and $95.7 \%$ had spent in total at least a month there. However, the role played by students during these prior visits is often circumscribed: on holidays or on school exchanges they are not independent actors within L2land society; any threat or conflict is mediated; they are in "relatively set, enclosed and protected situations" (Lillie, 1994: 4); this may help explain why familiarity with L2land appears not to prepare students fully for the cultural differences they will encounter.

\section{Study or residence abroad in the European context}

In a European context, the term "study abroad" is not the most usual way to refer to an extended sojourn in a foreign country which is an integral part of a university degree course. Until recently, one spoke of the "year abroad" — or even the "year away" or "year out" — until shorter periods became common. Today, "residence abroad" is the most widely accepted term, embracing the three most popular ways of spending the period abroad: as a foreign language assistant, on a work placement, or as a student. The majority of residence abroad placements are in fact at universities in another country - most often European but not excluding, for example, Japan, French-speaking Canada, Latin America, or French West Africa.

Europeans perceive American "study abroad programs" as the often short-term relocation of cohesive groups to a new geographical base, which may or may not be English-speaking, and where they benefit from formal (classroom) teaching but without necessarily abandoning the academic structures and support systems of the home institution. The European tradition is for longer stays - a full academic year in the majority of cases - and for students to be alone or in small groups and dependent wholly on local social, academic and institutional support systems. Whereas American students may have modest target language (L2) proficiency, European language students on mobility programmes will normally have advanced skills, typically at least ten years' teaching where the L2 is English, eight years' teaching in the case of UK students of French (Coleman, 1996a: 178), but less in the case of students of other disciplines. American and continental European students are similar in that 
individuals $o p t$ for residence abroad, whilst for the vast majority of British students of languages the stay is obligatory. In situ language instruction may take the form of specific classes for foreigners, or two-way translation classes at which both native speakers and visiting students are present.

Under the assistantship scheme, which in the 1960s and 1970s was the norm, at least for applicants in France, Germany and the UK, students give 12 hours of conversation classes in their native language in one or two secondary (recently also primary) schools in return for a small but adequate wage and often free board and lodging.

Work placements (internships) are increasingly popular among language students (Kloss \& Zemke, 1987), but are resource-intensive to organise and supervise. Patterns vary, but typically the student, in year three of her/his four-year degree course, will spend one or two semesters in a L2land company, receiving a minimum wage and some on-the-job training. To the benefits of experiencing the real world of work are added those of working in an exclusively L2 environment - although the company will often wish to use the student's L1 skills, for example in translating or liaising with L1-speaking customers. Within ERASMUS, 21\% of students include a work placement, particularly in certain disciplines such as agriculture and medicine.

\section{Residence abroad for United Kingdom- based students}

The UK merits special treatment since it has the largest intake of residence abroad students; the largest take-up of ERASMUS — it is the only major European country whose share of students on ERASMUS exceeds its proportion of the 18-25 population and of students in higher education (Teichler, 1997: 32); the most detailed studies of residence abroad of any individual country; and the highest degree of government involvement, leading to the definition of best practice.

Within European higher education, the British were pioneers of residence abroad. There were generic precedents, such as the Grand Tour which wealthy and aristocratic young men and women undertook in the eighteenth and nineteenth centuries to become familiar in situ with the cultural artifacts of Greece and Italy, or the Wanderjahre which tradition- 
ally allowed German students to get the best from a number of universities. And of course the universities of mediaeval Europe were fully international, with students frequently following classes, delivered in Latin, in whichever country offered the most reputed teachers. Michel de Montaigne, French philosopher, statesman and essayist, undertook a séjour à l'étranger, an Auslandsaufenthalt, in 1580-81, travelling across France, through Switzerland, to Italy, where he spent the best part of a year. Throughout his journey, he observed and recorded in a diary the customs, the sights, the daily incidents - and what he learnt from his increasing knowledge of the Other. He wrote his diary in Italian. Plus ça change ...

But it was in the early years of the present century that a programme of exchanges was established between the United Kingdom and France, building on the intuition that immersion in the target language community would bring linguistic benefits to the learner, while the host country would benefit from native speaker input in language classes in secondary schools. However, not until well after the Second World War did a year abroad become an integral part of nearly all language degrees in the United Kingdom; at Oxford and Cambridge it was still strongly discouraged even in the 1960s. Residence abroad is mandatory for students on modern language degrees, and for $37 \%$ of all UK ERASMUS students, a far higher proportion than for any other country: the figure for Italy is only 3\% (Teichler, 1997). UK students have also, at least until now, received state financial support: of those graduating between 1980 and $1984,60 \%$ of their costs were met by grants and loans, compared with only 20\% in Germany and 7\% in France (Opper, Teichler and Carlson, 1990: 150-151). Elsewhere in Europe, student residence abroad remained an expensive exception until the launch of European Union programmes to encourage student mobility.

Within the UK, in 1994/95 Coleman (1996a; cf data for 1986 in Meara, 1994) found that patterns varied according to the L2 of students $(n=4207)$ who had completed a period of compulsory residence abroad, but that the majority attend an L2land university during their period of residence, which typically lasts a full academic year (see Table 1). The increasing numbers of students learning two foreign languages normally split the period between two destinations, although some may choose to spend the whole year in a single L2land, perhaps with vacation residence in another. 


\begin{tabular}{|c|c|c|c|c|c|c|c|c|c|}
\hline \multirow[b]{2}{*}{ L2 } & \multicolumn{5}{|c|}{ Type of placement } & \multicolumn{4}{|c|}{ Duration } \\
\hline & Student & \begin{tabular}{|l|} 
Language \\
assistant
\end{tabular} & $\begin{array}{l}\text { Work } \\
\text { placement }\end{array}$ & $\begin{array}{l}\text { Combi- } \\
\text { nation }\end{array}$ & Other & $\begin{array}{l}\text { Less } \\
\text { than a } \\
\text { term }\end{array}$ & $\begin{array}{l}\text { A } \\
\text { term }\end{array}$ & $\begin{array}{l}\text { A } \\
\text { semester }\end{array}$ & $\begin{array}{l}\text { A } \\
\text { year }\end{array}$ \\
\hline French & 53.4 & 26.7 & 11.6 & 5 & 3.3 & 11.3 & 10.1 & 18.5 & 59.8 \\
\hline German & 53.4 & 19.7 & 17.3 & 5.9 & 3.6 & 9.5 & 7.1 & 20.9 & 61.6 \\
\hline Spanish & 72.5 & 9.7 & 8.9 & 3.9 & 5 & 15.3 & 8.3 & 21.4 & 54.4 \\
\hline Russian & 91.8 & 0.4 & 2.9 & 3.3 & 1.6 & 24.2 & 29.9 & 21.3 & 24.6 \\
\hline
\end{tabular}

British universities are diverse. Not only are there different educational structures and traditions in each of the four countries which make up the United Kingdom — in Wales, for example, children in primary school whose mother tongue is English learn Welsh, while in Scotland and Northern Ireland the school-leaving/university entrance examinations are broader in scope than in England - but additionally British higher education institutions (HEIs) enjoy greater autonomy than in most other European countries. However, the vast majority of Europe's universities are state-funded public institutions; in the UK, the near totality of HEIs depend on state funding, and recent governments have sought to balance autonomy with transparency and accountability through national programmes of quality assessment. Several other European countries are set to follow the UK's lead, hence the interest of the UK initiatives.

In 1995/96 the UK's Higher Education Funding Councils carried out a Quality Assessment of provision in modern languages. Teams of peer assessors visited institutions in England, Wales, Scotland and Northern Ireland and evaluated the quality of education against the institution's own aims and objectives, on the basis of documentation, observation, and discussion with those involved. The published reports on every modern language department in the country (http://www.niss.ac.uk/education/hefce.qar/) represent the widest and most recent survey of practice anywhere in Europe, albeit not the most detailed.

Subject Overview reports (HEFCE, 1996) identified residence abroad as a distinctive and valuable feature of provision, often charac- 
terised by effective preparation in the form of practical/academic handbooks and videos, a structured programme of meetings with staff, feedback from returners, "cultural transition" workshops, TEFL (Teaching of English as a Foreign Language) training when required; by support during residence abroad through establishment of clear aims and objectives, staff visits, local link-persons, student learning contracts, learner diaries or "personal development" files; by debriefing and reflection on return. Assessors noted benefits in linguistic competence, confidence, maturity and transferable skills such as planning and organisational competences. Occasionally the student gains dual (UK and L2land) qualifications.

However, the overall report highlights significant failings in residence abroad provision to be the most significant issue of all in university modern language provision in the UK. The assessment found shortcomings in preparation, which was "minimal" in some cases; in curriculum integration, with two-thirds of French and German departments failing to integrate residence abroad successfully, and a particular failure to build on linguistic progress achieved; in assessment, with the results of L2land residence rarely making a significant contribution to degree classification; in support while abroad, with only a quarter of institutions making pastoral visits, and others relying on casual visits, letters, phone calls or email. In Spanish and Portuguese, for example, "the aims and objectives of the period abroad are not fully identified and explained to students; the assessment, certification, monitoring, quality control and outcomes expected are also often vague and undeveloped. Many institutions are criticised for their lack of design, planning, operation and evaluation of the period abroad and its place within the curriculum as a whole" (HEFCE, 1996, 4/96: 20). Thus, although within Europe the UK has the longest experience of incorporating residence abroad in language degree programmes, actual practice still falls short of the ideal.

The Fund for the Development of Teaching and Learning (FDTL) seeks to address the issues identified. In 1997, from bids submitted by consortia of institutions which had achieved high ratings in the Quality Assessment process, three projects concerning residence abroad were selected for funding at $£ 250,000$ each over three years. Although no results are published as yet, a full national survey of current practice has been carried out, a number of pilot evaluations are under way, and two new websites have been created. The National Residence Abroad Database 
(http://nrad/fdtl.ac.uk/nrad/index.htm) will carry in searchable and summary form the results of the national survey; it already houses a database of all paragraphs of Quality Assessment reports, searchable by institution, language and topic; the research bibliography from Coleman (1997); an announcement board and discussion group. The Our Year Abroad website (http://www.port.ac.uk/slas/abroad/frame.html) is a prototype designed for student use, with links to partner universities and the cities where they are located, helpful practical documentation, a transferable-skills development programme, and a facility for students to tell each other about residence abroad experiences - such advice inevitably carries more credibility than counsel from academics. The website will be used in 1998-99 for "virtual visits" — student-student, staff-student and staff-staff videoconferencing via the internet.

\section{Research Findings}

\section{Introduction}

This section, after some preliminary remarks on the type of publication reviewed, looks at EU programme evaluation reports, at UK studies, at findings concerning linguistic proficiency, and at other research issues.

Coleman (1997), in a "state-of-the-art" article in the abstracting journal Language Teaching, reviewed current research worldwide into linguistic aspects of residence abroad. The article covered independent variables by category: affective (motivation, attitudes, anxiety, personality, acculturation and culture shock), cognitive (aptitude, learning style, learning strategies), biographical, linguistic and circumstantial. In the present article, only specifically European findings are highlighted, and research whose subjects are not precisely comparable (school-level learners; non-European learners; less proficient speakers; wholly naturalistic or wholly tutored learners - our subjects lie between the two) have generally been excluded. In considering the generalisability of research findings, it should be noted that much research concerns language specialists, whilst most university students of foreign languages, and most of those on SOCRATESERASMUS programmes, are in fact specialists in other disciplines. It should also be noted that many university learners of English have a different, more 
instrumental, motivation from learners of other L2s (Coleman 1996a: 131). This, too, may affect the generalisability of findings.

A further problem is the nature of much that has been published on residence abroad. Those responsible for language teaching and for the curriculum, including residence abroad, in many European universities, are not only untrained as teachers, but are also specialists in wholly different areas, often literary or cultural. They do not necessarily have any grounding in applied linguistics, and have a very different research paradigm. They are concerned with the totality of the process, including administrative, financial and pastoral questions, and not merely with language outcomes. Some published material is therefore difficult to integrate, but at the same time, such evaluative reports often represent accumulated experience and wisdom, and cannot be dismissed.

\section{Evaluation of European Union programmes.}

Residence abroad in Europe has been the subject of two major evaluations: Opper, Teichler and Carlson (1990) conducted an extensive analysis, mostly by questionnaire, of students on 82 study abroad programmes. 416 subjects looked retrospectively at 1983-84 experiences, 458 graduates provided information on subsequent employment, and 439 students provided information both before and after 1984-85 programmes, of which 22 "home" institutions were in the UK, 14 in France, 26 in Germany (West, as it was then), 8 in Sweden and 12 in the USA. It included "Joint Study Programmes" which were the precursor of ERASMUS. Reliance on self-reporting and self-assessed proficiency limits the value of the data, but the study did suggest an increase in proficiency across all language skills, greatest gain by weakest students, and smaller gain by specialist language students than by students in other disciplines.

Pre-residence abroad US students were less proficient in the L2 than their European counterparts. Perhaps because of high individual variation, multivariate analysis showed no overall correlation between proficiency gain and passive (reading) or interactive contact with L2landers, although for some groups there was a link with reading, with new types of coursework, and with museum visiting. The variation in results leads the authors (op.cit.: 107) to suggest that analysis of factors other than those tabulated, including previous study and the particular L2, would be valuable. 
The study also notes a decrease in the "degree of restraint" felt in using the L2, with US students most restrained at the start, and all students "only minimally restrained" (op.cit.: 113) at the end of residence abroad. The degree of "restraint" decreased most among students who followed language courses other than or additional to those specifically linked to the study abroad programme. However, it is unclear to what extent the "restraint" data refer to perceived proficiency, and how far to language anxiety. The authors conclude, however, that "American students face comparatively greater problems in communicating in a foreign language abroad (starting from a much lower proficiency level)" (op.cit.: 113).

The authors find a link between type of accommodation (dormitory/student residence, apartment, family) and the type of social contact with L2landers, but the question referred to "shaping the overall experience abroad" (op.cit.: 46-7) rather than to specifically linguistic contacts.

The study also shows an overall increase in (self-reported) cultural knowledge of L2land, but, interestingly, finds no associated increase in empathy towards the foreign culture. The measures of attitude are, however, rather intellectual ones: government foreign and immigration policy, higher education, cultural life, media, customs and traditions, and social structure. Changes in views of L2land and L1land are marginal, although "the attitude toward home country became slightly more positive after study abroad than it had been before, but the difference was not statistically significant" (op.cit.: 122-4), cf Willis et al. (1977) and Coleman (1996a) below. There is increased global awareness only where the group are less globally aware before departure. In much of the data, there are clearly factors at work which go beyond those analysed: for example, $28.1 \%$ of European students return much more cosmopolitan, but $14.8 \%$ much less cosmopolitan, and similar opposing movements are observed on self-confidence. Two-thirds of 102 students on work placements found them more beneficial than study abroad. Throughout, there is substantial individual variation.

Teichler (1997) synthesises the extended evaluation of the ERASMUS programme from 1988 to 1995 undertaken by the team at the University of Kassel. This invaluable and authoritative study addresses administrative and academic questions, takes students' views, and examines the impact of residence abroad on their achievements and subsequent careers, as well as looking at academic recognition and spin-offs for par- 
ticipant institutions. It includes a bibliography of 49 more specific ERASMUS-related studies. Teichler draws on data up to $1992 / 93$, including over 3000 confidential student questionnaires administered in 1988/89 and again in 1990/91, 5000 contractual student reports from 1990/91, follow-up surveys in 1992 and 1994 of the 1988/89 cohort, coordinator reports from 1989/90 and 2700 questionnaires completed in 1991/92, as well as statistical data which presents a full picture of the evolution of the ERASMUS programme.

Learning a foreign language dominates the reasons for studying abroad, being cited as 1 ("strong influence") or 2 on a five-point Likert scale by $86 \%$ of respondents. This is followed by self-development ( $81 \%)$, academic learning in another country $(77 \%)$, enhanced understanding of L2land (72\%), travel (62\%), wanting a break (56\%), experience of new teaching methods (49\%) and the desire to gain another perspective on one's own country (49\%). British and Irish students typically go during their third year at university, other nationalities in the fourth or fifth, which may be after graduation from the first degree. The mean length of stay is 6.6 months; in 1993/94 16\% stayed for three months or less, $43 \%$ for $4-6$ months, $41 \%$ for 7-12 months. Within ERASMUS (as opposed to residence abroad generally), $72 \%$ of programmes include only university study, and a further $17 \%$ some element of university study; other activities include work placements and thesis preparation. There is formal written certification in the majority of cases, ranging from a double degree to a simple written attestation.

Virtually all institutions provide preparation, through meetings, written material, mandatory or optional courses and self-study. Preparation addresses practical matters (85\% of institutions), improving L2 proficiency (75\%), academic (67\%), and cultural (64\%) questions. Returners are used in briefings in $36 \%$ of cases, visiting L2landers in $24 \%$ (1991/92). There are very substantial differences between what staff claim to provide and what students claim to have received. Levels of student satisfaction with support provided are less than enthusiastic, but satisfaction with the experience and with the academic, professional, linguistic and personal/cultural benefits is very high.

Attitudes were assessed on the basis of a similar list to that used by Opper, Teichler and Carlson (1990), including higher education, government foreign, domestic and immigration policies, urban life, etc. Again, 
stability of average judgments across the period of residence abroad concealed substantial shifts in both directions in a minority of cases, but there was no evidence at all that increased knowledge of the L2land society leads to more sympathetic judgments of the country as a whole.

While pre-residence abroad L2 proficiency varied across subject areas and L2s, overall similar and substantial progress (between self-assessed proficiency levels) was observed across all four skills, and in both academic and non-academic settings. Five years later, graduates perceived little average loss, although the degree of loss correlated with the level of L2 use in a work context in the interim. Knowledge of L2land also improved across a range of topics, especially higher education, and graduates felt that they retained this knowledge. Teichler sought by multiple regression analysis to identify factors related to increased L2 proficiency, and found five factors, both individual and institutional: having a linguistic objective in undertaking residence abroad; following language classes in common with native L2-speaking students; academic preparation in the home university; teaching in the L2 at the host university; and frequent cultural activities while abroad.

While many of these findings will apply equally to non-ERASMUS residence abroad, it must be recognised that the danger of socially desirable responses is high where the body funding the study is also funding the residence abroad programme from which the subjects, both staff and students, are benefitting. For example, figures for self-reported "frequent" contact with L2land may be inflated: $72 \%$ frequently read or listened to news, $64 \%$ had frequent conversations with L2land students; $57 \%$ conversations with other L2landers; $55 \%$ conversations with L2land teaching staff; $60 \%$ joint leisure activities with L2landers; $58 \%$ travel in L2land; $66 \%$ visits to museums/theatres/concerts. To those familiar with European universities and the pressures on staff, it might seem surprising that such a high number claim to have frequent conversations with teaching staff virtually the same percentage as contacts with all other representatives of the target community put together. And the two-thirds asserting frequent cultural activities are clearly dissimilar from my second-year, pre-residence abroad students of French: in two years, not a single one of over 100 had set foot inside the Portsmouth city museum located opposite the university students' union! 


\section{UK Studies}

Apart from the EU evaluations, residence abroad in Europe has been the subject of three major UK studies by Willis et al. (1977), Dyson (1988) and Coleman (1996a), and was one element of an uncompleted national survey whose data was analysed later (Meara, 1994). "The year abroad" is also the focus of a volume of collected papers.

Willis, Doble, Sankarayya and Smithers (1977) sought to evaluate gains in speaking, listening comprehension, and sociocultural knowledge, as well as changes in attitudes and anxiety, and to explore the circumstantial factors involved. 88 students at Bradford University completed a total of 24 study placements and 84 work placements in France or Germany in $1983 / 84$ or $1984 / 85$. Materials consisted of a multiple-choice listening comprehension test, three speaking tests, a multiple-choice test of sociocultural knowledge, four attitudinal questionnaires (covering attitudes to the value of residence abroad, perceived L2 oral proficiency, reasons for going abroad, and experience while abroad), two biographical questionnaires and three personality measures — the Cattell Personality Inventory, Rokeach Dogmatism Scale, and a semantic differential allowing respondents to evaluate real self, ideal self, L1landers and L2landers on a range of personal qualities, some of which related to national stereotypes. New measures were validated by pre-testing, and all were administered before and after residence abroad.

Students' reasons for going abroad were principally to improve their L2, to gain first-hand experience of L2land culture, and personal development. Like Teichler's ERASMUS students - and the response may be typical of many other groups - the Bradford students felt they had been insufficiently prepared, especially linguistically and with regard to the type of placement. On personality measures, work placement students returned more conscientious, venturesome and open-minded with an enhanced self-image, while the study placement group showed less change. Both the French and the Germans were re-appraised: post-residence abroad students saw the French as more hard-working, submissive, kind, dependable, tolerant, carefree, cheerful, intelligent and international, but also more impatient, excitable, quick-tempered, conservative and prejudiced; and the Germans as more intelligent, dependable, generous and clean but also less efficient, more prejudiced, impatient and excitable 
than they had been judged pre-residence abroad. The results concerning L2landers are thus more mixed than those of Coleman (below), but are consistent on L1landers, since overall, "British people were rated more favourably after the year abroad, with more positive evaluations of their patience, dependability, intelligence, friendliness, kindness and honesty" (op.cit.: 72).

Residence abroad enhanced listening comprehension and speaking in most cases, albeit with high individual variation and some deterioration in performance; weaker students made most progress. Little increase in sociocultural knowledge was measured. Small samples, and the fact that stronger students were selected for work placements weakens the conclusion that the latter brings greater gains in oral skills, especially in formal situations, although the work placement students had also (self-reportedly) spent more time speaking L2 and less speaking English than had the study placement students. There was a statistical link between improvement in speaking skills, positive attitudes to speaking, and actual reported use of the L2. The researchers compared enhanced skills with personality factors, and found introverts made greater progress in listening skills, extroverts in sociocultural knowledge, and the open-minded, less anxious and person-oriented in productive skills.

In the longitudinal study reported by Dyson (1988), 118 students of French, 83 students of German and 28 students of Spanish, all selfselected volunteers, took a battery of speaking and listening tests (controlled for reliability) before and after residence abroad. Only 28 students of French studied at a L2land university: the others were foreign language assistants, although 10 students of French and 3 of German, all studying two languages, went to a country where their target language was not spoken. Not unexpectedly, these students made less or no progress in speaking and listening. All other groups made substantial progress on both skills, with weaker students making greater progress. Respondents assessed their own gains as lying principally in speaking, listening, L2land knowledge and self-confidence, with modest gains in reading competence and little in written skills. Meara (1994: 32) regrets the absence from the Dyson study of tests of other linguistic skills, the impressionistic marking, and the lack of a control group, and asserts that much of the average gain is explained by the considerable improvement of weaker students.

Coleman (1996a, 1998a) reports on the European Language 
Proficiency Survey, a repeated cross-sectional study involving in all over 25,000 students between 1993 and 1995. In autumn 1993 a questionnaire covering biographical data, background, course information, attitudes, motivation, and metalinguistic knowledge was administered to 3,119 respondents studying French, German, Spanish, English and Russian in the UK, and 295 students in Germany and Austria, together with a CTest (a measure of general language proficiency); in autumn 1994, a revised form of the questionnaire, with questions on transferable skills replacing those on metalinguistic knowledge, and a new C-Test was administered to 18,825 UK-based students of French, German, Spanish and Russian and 2,766 students of English, French and German in seven other European countries. The findings relative to residence abroad concern proficiency, motivation, attitudes and anxiety, and are reported in the appropriate sections below.

Meara (1994) summarises the Willis et al. (1977) and Dyson (1988) studies before analysing some of the data collected by questionnaire from 586 language specialist students in 1986, a carefully structured sample but which may over-represent high-flyers in prestigious universities. Respondents estimated whether they had spent a little or a lot of time speaking the L2, and how far each of their four L2 skills had improved. As in other studies, a large majority felt their oral skills had improved considerably, but reading and writing were seen as making far less progress. There is a significant difference by type of placement, with those on study placements $(n=301)$ perceiving lower progress in speaking and listening than those $(n=210)$ on work placements. There is a clear correlation between (self-reported) time spent speaking the L2 and (self-reported) gain in each of the four skills. Additionally, students rated highly their increased knowledge of L2land and personal skills, but were less convinced of their enhanced employability.

In 1995, Parker \& Rouxeville edited a volume devoted entirely to "the year abroad" (Parker \& Rouxeville, 1995a). The introductory chapter (Parker \& Rouxeville, 1995b) underlines how, although British universities have been sending students abroad for many years, critical reflection on practice is a recent phenomenon: a searching review of every aspect of teaching and learning in modern languages departments in 1989 (HMI, 1989) simply does not mention the quarter of the degree course which takes place elsewhere, while the profession's own guidelines date only 
from 1991. The book contains eleven other chapters in the first of which Coleman (1995) summarises current practice and reviews research into L2 proficiency gains.

Murphy-Lejeune (1995) reviews theoretical approaches to the "stranger," contrasts European quantitative studies with American studyabroad literature, finding in the latter a clinical flavour, with residence abroad a disruptive experience requiring therapeutic treatment. She also notes a difference in treatment of in-comers and out-goers, and problems encountered in the statistical analysis of numerous psychological variables, and proposes a sociological theory of cross-cultural adaptation open to qualitative, empirical validation. She finally discusses the initial findings of a study based on semi-structured interviews of 60 students in different residence-abroad roles: ERASMUS students, students of English for academic purposes, and foreign language assistants. Murphy-Lejeune's $\mathrm{PhD}$ thesis based on the study is to be presented in 1998 and is eagerly awaited.

Cormeraie (1995), who also provides intercultural training for business (Harper \& Cormeraie, 1995) describes a cross-cultural training programme for students rooted in anthropology, designed to help students understand their own cultural identity, and thus appreciate how beliefs and values are encoded in other cultures, as a prerequisite for the self-confidence, attitudes and behaviours necessary if the potential linguistic and other benefits of residence abroad are to be realised. Drawing on a number of theorists, she explains the rationale and the practical arrangements for addressing in an integrated (cognitive, affective and behavioural) way the fears, prejudices, stereotypes and expectations of the students. Evaluation has shown that students prepared in this way cope better with the unpredictable and potentially conflictory when abroad.

Jordan and Barro (1995; cf. Barro and Grimm, 1993; Barro, Jordan \& Roberts, 1998; Roberts, 1997) describe how students receive practical ethnographic training before departure to provide them with "a more critical and differentiated understanding of otherness" (op.cit.: 78), and complete a project in the UK which gives them the necessary skills to operate abroad as "participant observers." Allison and Hintze (1995) analyse the issues and solutions involved in practical, linguistic and sociocultural preparation. Dueñas-Tancred and Weber-Newth (1995) and Convey (1995) detail how students can be helped to develop personal objectives and strategies, 
and to keep a log profiling their learning in L2land, so that linguistic proficiency, cultural knowledge and transferable skills acquired in L2land can be assessed and accredited, thus overcoming one of the obstacles to take-up of the residence-abroad option by European students, and providing evidence of ways in which the experience enhances employability.

Rider (1995) describes the structured study visit: a shorter alternative to a year abroad which nonetheless ensures maximum linguistic, cultural and academic gain; Aldridge (1995) relates an arrangement for students to be assistants in primary schools; Jamieson (1995) evaluates a project-based preparation for assistantship; and Noreiko (1995) reviews some of the variables involved in the residence abroad experience, as Inkster (1993) had done in a previous volume.

\section{Language proficiency gains}

The oft lamented paucity of European studies of changes to L2 proficiency during residence abroad may be attributable in part to the orientation of research interests of staff in those departments which send students abroad: very few conduct research into second language acquisition. Nonetheless, we have seen that studies based on self-assessed proficiency (Opper, Teichler \& Carlson, 1990; Teichler, 1997) suggest that L2land residence raises overall proficiency substantially, and other cross-sectional and longitudinal studies support the assertion. Gomes da Costa et al. (1975) administered the Modern Language Association of America's Advanced Proficiency Tests (listening, speaking, reading, writing) to 171 final-year students of German in 1970. The students were following predominantly literary courses at UK universities, and had above-average language qualifications. Over $90 \%$ had spent one or more extended visits to Germany within their course (op.cit.: 39-40), and the total time spent correlated $(\mathrm{p}<.01)$ with scores on speaking, listening and writing, although not with reading. In a small longitudinal study, Alderson \& Crawshaw (1990) measured the performance of 17 incoming ERASMUS students on well-established English placement tests with four components (grammar, reading, listening, writing), and noted an improvement across the board. There was a ceiling effect, but progress was measurable whether the students followed one term or two of language instruction: the small sample allows no other conclusions. 
Milton \& Meara (1995) used a criterion-based vocabulary test to measure progress in English of 53 European students in the UK during 1991/92. The test estimates the absolute size of the learner's L2 vocabulary, and allows calculation of the number of new words learned, the percentage growth in vocabulary, and, by dividing entry vocabulary by number of years of prior study, comparative rate of vocabulary acquisition in L1land and L2land. Despite the substantial individual differences which are a recurring feature of residence abroad research (individual growth scores ranged from 3800 words to 900 words), and the fact that weaker testees progressed fastest, students increased their English vocabulary by an average of $23 \%$ in six months, achieving a projected annual growth rate of 2600 words a year as compared with a mean of 500 to 600 at home. There was no correlation between vocabulary growth and L1, length of prior L2 study, or — disappointingly — contact with L2landers, but a weak negative correlation with study: more diligent students acquired fewer new words, perhaps because they integrated less fully into L2land society. The only other significant links were with accommodation type (family > flat $>$ hall of residence) and with perceived success at language learning. Vocabulary gains are also attested by Lennon (1990b) and Walsh (1994).

The conclusions of Coleman's European Language Proficiency Survey (Coleman, 1996a) rely on C-Test scores. The C-Test is a valid, reliable and aboveall eminently practical proficiency measure for large-scale studies, but it has no oral-aural component and does not differentiate between the sub-skills which make up L2 proficiency. Coleman's was a reiterated cross-sectional study: i.e., no pre- and post-residence abroad testing was carried out on the same students. However, the samples were very large and may be taken to be representative of proficiency levels of the population of students in question. Across the four target languages, mean scores for year $4 / 5$ students (i.e post-residence abroad: Scottish students have a five-year undergraduate programme) are substantially higher than pre-residence abroad scores (see Table 2). Although these figures do not prove that residence abroad leads to increased L2 proficiency, they are certainly consistent with such an explanation, and indeed with the hypothesis that the contribution of residence abroad to the foreign language proficiency of advanced learners is greater than that of a year's instruction in the home institution. The figures for virtually all individual departments, 
listed in Coleman (1996a), are also consistent with the explanation. These results replicate Coleman's pilot study in which 2,368 students of the same four languages took a different C-Test (Coleman, 1996b).

\begin{tabular}{|c|c|c|c|c|c|c|c|}
\hline Language & Unis* & $\begin{array}{l}\text { Number } \\
\text { of Year } 1 \\
\text { students }\end{array}$ & $\begin{array}{l}\text { Number } \\
\text { of Year } 2 \\
\text { students }\end{array}$ & $\begin{array}{l}\text { Number } \\
\text { of Year } 4 / 5 \\
\text { students }\end{array}$ & $\begin{array}{l}\text { Year } 1 \\
\text { mean } \\
\text { score }\end{array}$ & $\begin{array}{l}\text { Year } 2 \\
\text { mean } \\
\text { score }\end{array}$ & $\begin{array}{l}\text { Year } 3 \\
\text { mean } \\
\text { score }\end{array}$ \\
\hline French $\dagger$ & 75 & 5115 & 4008 & 2372 & 51.38 & 56.75 & 70.34 \\
\hline German $\dagger$ & 55 & 1511 & 1135 & 829 & 44.50 & 47.51 & 65.51 \\
\hline Spanish $\dagger$ & 44 & 704 & 911 & 513 & $77.48 * *$ & $73.31 * *$ & 91.91 \\
\hline Russian $\dagger$ & 16 & 65 & 175 & 213 & $30.69 * *$ & $26.88 * *$ & 44.18 \\
\hline
\end{tabular}

* Number of university departments taking part.

** Year 1 scores for students of Spanish and Russian are higher than Year 2 since the former includes only those who have studied the language at school, whereas by Year 2 those who began the subject at university are also included.

+ Maximum scores in French and Russian 100, in German 110, in Spanish 125.

The fall in standard deviations between Year 2 and Year 4/5 groups was very marked in French and present in Spanish and German (though not in the much smaller Russian sample), which suggests that residence abroad reduces the heterogeneity of the learner group, i.e. that weaker students make greater progress. The French Year 1 group scores showed a standard deviation (SD) of 15.53; Year 2 of 15.67, and Year 4 of 12.08. In German and Spanish Year 1 SDs were lower than those of Year 2, probably because ab initio students are excluded from Year 1 figures but have been integrated into the teaching groups by Year 2. Nonetheless, in both languages the SD reduces between Year 2 and Year 4/5, in German from 18.68 to 17.29 and in Spanish from 21.60 to 16.40 .

Coleman found significant correlations for all four L2s between proficiency levels and the total time spent in L2land; the number of visits also 
correlated. However, links between proficiency levels and type of placement, and between proficiency levels and duration of stay can be explained by the residence abroad arrangements favoured by the type of institution which attracts the best qualified and already more proficient students.

Coleman also looked on a smaller scale at changes in proficiency after return from residence abroad. A pilot study of 29 learners of German, tested in October 1993 and retested in June 1994, suggested that the mean improvement in C-Test score from $81.6 \%$ to $83.2 \%$ might be accounted for by test-retest effect, and that language instruction following residence abroad might no longer raise proficiency (although there may also be a ceiling effect) (Coleman, 1996b). A cross-sectional pilot study (Coleman, 1996b) of 136 students of Spanish across two post-residence years of study also failed to show any significant difference in proficiency (October immediately following return, mean score 81.5, $n=75$; October one year after return, mean score 82.2, $\mathrm{n}=61$ ), and reinforced the conclusion, which also finds support in a substantial North American study (Raffaldini, 1987). Fifty students of French, tested in October 1994 and retested in June 1995 likewise showed no improvement (mean scores 69.36, 69.32). Even if the extreme cases are excluded ( 4 who improved most, 4 who deteriorated most), the mean scores at 70.1 and 69.8 tell the same story (Coleman, 1996a). There is no evidence of a ceiling effect here, although it is possible that the $\mathrm{C}$-Test does not measure the type of gains (i.e. the sub-skills) made by language students after residence abroad. It is equally possible that successful completion of residence abroad changes the perceived learning needs and thus the intensity of motivation: further research is required, but it appears that return from residence abroad marks the high point of $\mathrm{L} 2$ proficiency, which can thereafter decay.

Mastery of L2 grammar may improve during residence abroad: Lennon (1990b) reports greater syntactic complexity and a reduction in errors in his longitudinal study of four German students during a sixmonth stay in England. Walsh (1994), who used pictures to elicit L2 samples from 15 Irish students of German before, during and after residence abroad in 1991/92, identified some morpho-syntactic progress in some students, but no significant grammar gains were found in an extended study of German students in France (Möhle \& Raupach, 1983; Möhle, 1984; Raupach, 1987) or a longitudinal study of Irish students in France 
(Regan, 1995).

The two British longitudinal studies (Dyson, 1988; Willis et al., 1977) found substantial improvement, as we have seen, in oral-aural skills, although there was considerable individual variation, and weaker students made more progress. Dyson's respondents, like their contemporaries in the study analysed by Meara, also felt intuitively that their progress had been essentially in listening and speaking rather than reading and writing: self-reported gains were thus apparently confirmed by objective measure. Questionnaire data from 7 Irish ERASMUS students who had spent six months in France or Francophone Belgium (Batardière, 1993) similarly show self-reported gains concentrated in oral-aural skills, with no perceived gain in writing.

The problematic definition and measurement of oral proficiency and fluency is addressed by Lennon (1990a, 1990b, 1995; cf the review in Freed, 1995, and Walsh, 1994), who used two picture stories to test and retest four German students during a stay in England. Against criteria of productivity, syntactic complexity, correctness, fluency and content, teachers' subjective assessments were unreliable, and even objective analysis of transcripts found progress over two months in only the second and fifth categories. Over six months, however, and despite high individual variation, there was overall fluency gain, but this could be quantified on only three of twelve fluency measures. The measures were either temporal or concerned the absence of dysfluency markers. The subjects showed significant increase in "pruned" words per minute (excluding self-corrections, non-deliberate repetitions and asides), and decrease in filled pauses per T-unit ("er," "erm" and so on, where the T-unit is a main clause with all its subordinate clauses and phrases), and in the percentage of T-units followed by pauses.

Walsh (1994) reports gains in fluency by Irish students of German, while Towell's longitudinal study of twelve learners of French shows the crucial importance of residence abroad to the development of fluency in the target language (Towell, 1994, 1995), attributed (Towell, Hawkins \& Bazergui, 1996) to the proceduralisation of declarative L2 knowledge, and measured according to principally temporal variables (speaking rate, phonation/time ratio, articulation rate, mean length of runs). A similar hypothesis emerges from Laudet's longitudinal study (1993) of three Irish students of French for Business. Laudet noted substantial increases in flu- 
ency, which are interpreted as improved language processing resulting from residence abroad. The speaking rate (syllables per minute), articulation rate (syllables per second of actual speech) and phonation/time ratio (percentage of total time spent speaking) all increased significantly. The native-like quality of the students' speech was also enhanced by a reduction in pauses, both unfilled and filled (euh...), in drawls (extended vowels) and repetitions, all of which allow the learner additional time for thought and for language processing. Laudet concludes that "during their stay abroad students have refined their own way of coping with processing difficulties and have developed ways of sounding more like native speakers while giving themselves time to think" (Laudet, 1993: 22). Many researchers retain suspicions (reviewed in Coleman, 1996a: 85) that as far as fluency and oral-aural skills are concerned, learners acquire the disguise of the native speaker rather than the identity, the convincing performance and not the underlying competence. Gains in sociolinguistic competence, attested by Möhle and Raupach (1983) and Regan (1995), do not invalidate this hypothesis.

\section{Other residence abroad research}

As well as having a direct influence on language proficiency, residence abroad impacts on three factors which have long been identified as key variables in the language learning process: anxiety, attitudes and motivation. The question of preparation, and particularly of the development of intercultural competence, is central to European research on residence abroad.

\section{(1) Anxiety}

If we are to accept self-reporting, the experience and proficiency gain which residence abroad brings reduce the language anxiety felt by learners (Coleman, 1996a; Willis et al. 1977); it also levels out the difference between the sexes: prior to going abroad, British females report higher levels of anxiety (Coleman, 1996a). Willis et al. found that lower anxiety, allied to a more open-minded, more person-oriented personality, correlated with greater progress during residence abroad. 


\section{(2) Attitudes and stereotypes}

Like their American counterparts, European students acquire stereotypes at a young age; rooted in the society and culture in which the individual grows up, they have both an affective and a cognitive component; they become fixed during primary and secondary schooling, and can hardly be altered even by explicit teaching (Byram et al., 1991; Cain, 1990; Chambers, 1994), although Morgan's review article on foreign language culture learning (1993) adopts a more optimistic stance. European students hold firm stereotypes of their fellow-Europeans and of their own nations: such stereotypes are never undermined by actually living in the L2land concerned, and may actually be reinforced by residence abroad (Coleman, 1996a, 1998a), perhaps because learners select from their observations only what confirms their established views (Morgan, 1993).

Both Willis et al. (1977) and Coleman (1996a) found that residence abroad had an effect on attitudes. Coleman's repeated cross-sectional study elicited data on attitudes through a question asking respondents to rate L1landers (compatriots) and, separately, L2landers on a Likert type scale, against a series of personal and inter-personal qualities. The qualities were listed individually, in contrast to the traditional semantic differential technique. The study found consistently, but counter-intuitively, across eight sample populations totalling over ten thousand students, that postresidence abroad students had significantly more negative perceptions of L2landers than did pre-residence abroad students, with the shift towards a less positive view noticeable in between $8 \%$ and over $30 \%$ of respondents (Coleman, 1998a). The movement was strongest among students of Russian, and was more noticeable on inter-personal qualities such as helpfulness or tolerance towards others than on personal qualities. There was often a corresponding increase in ethnocentricity, i.e., an increase in positive perception of L1landers on precisely the same qualities. The changes were also significantly linked to the form of residence abroad: for example, Britons studying at a French university are less likely than are assistants or peers on work placements to find the French helpful, goodhumoured, tolerant and friendly, but are more likely to find them hardworking, serious and arrogant. The experience of an assistantship tends to make students rate the French as more emotional and inefficient, while working with them encourages a perception of them as patient, tolerant, 
and less arrogant than might have been expected (Coleman, 1998a). Before and after residence abroad, the judgment of females is more generous than that of males (Byram et al., 1991; Cain, 1990; Coleman, 1998a).

\section{(3) Motivation}

Studies of the motivation to language learning of European university students, whether Irish (Singleton \& Singleton, 1992), German, Finnish and Belgian (Schröder \& Macht, 1983), or British (Coleman, 1996a; Evans, 1988), have consistently shown both an integrative and an instrumental orientation, together with a classroom factor linked to the enjoyment of the language as a subject of study and to perceived success in learning. An instrumental orientation seems to be a poor predictor of success as far as languages other than English are concerned (Gomes da Costa et al., 1975; Coleman, 1996b). That the precise pattern of motivation varies across the nations of Europe has been demonstrated by Coleman (1996a, 1998b) and by Kennedy and Schröder's study (1992) of 2436 students at 10 universities in Ireland, the UK and the Netherlands, which in turn builds on Schröder and Macht's study (1983) of 1916 university students in 3 German, 2 Finnish and 1 Belgian university). Coleman (1996a) finds a marginal difference in motivation between preand post-residence abroad students: the latter show rather more integrative orientation.

\section{(4) Preparation and intercultural competence}

Preparation for residence abroad, however imperfect (HEFCE, 1996), is nevertheless widespread in the UK as elsewhere in Europe (Teichler, 1997), taking the form of meetings, briefings, handbooks and packs, as well as specifically targeted course modules. Preparation is naturally matched to the many objectives of residence abroad: linguistic, academic, cultural, intercultural, professional and personal. Sociolinguistic preparation for the cultural dimension of discourse can obviate certain problems (Mauranen \& Markkanen, 1994), and there is evidence of the type of cross-cultural problems which can arise - and some solutions in an account of Irish students of German (Watts, 1994). But particular importance attaches to the development of intercultural competence: the 
combination of attitudes, feelings, knowledge and strategies which will allow students to benefit most from residence abroad. Students' openness to other cultures will clearly influence their attitudes and actions in L2land, which in turn will impact upon their language learning. A recent French doctoral thesis studying school pupils' perceptions of the English language, English native speakers and the language learning process (Berger, 1997) even argues that inappropriate social representations of the Other are the major obstacle to successful language learning.

Byram and Zarate (1997: 14-22) have usefully defined intercultural competence as consisting of four savoirs: savoir apprendre, savoirs, savoir être, and savoir faire. Savoir apprendre is a matter of understanding otherness, of using and creating opportunities for observation, analysis, insight and interpretation. Savoirs embrace cultural knowledge, including sociolinguistic competence, and an awareness of non-explicit reference points such as values, beliefs, and meanings. Savoir être is both affective and cognitive, covering attitudes and values, including understanding how one's own identity and culture are socially constructed; setting aside ethnocentric attitudes and perceptions; openness and interest towards others; inter-cultural mediation. Savoir faire means the integration of the other three in real L2land interactions.

Coleman (1998c) echoes the widespread belief that the learning or acquisition of intercultural competence requires more than a merely cognitive approach, and provides some examples of experiential learning designed to make students aware of the relativity of culturally-grounded values and behaviours, and the strategies to adopt while abroad. Lillie (1994) describes a survey of pre- and post-residence abroad students in Northern Ireland, and how unrealistic expectations concerning integration and cultural difference which had undermined the experience for one generation of students led to the development of a two-day intensive course including tasks and role plays to help students appreciate and cope with the reality of cultural difference. A major EU-funded project addressed the training of language teachers to address intercultural competence (Sercu, 1995).

Other specific initiatives to develop intercultural competence often build on the analogy between cultural learning and ethnographic research. One major project alluded to above, once again addressing both cognitive and affective dimensions, has included training students to carry out an 
ethnographic project on arrival in L2land (Barro \& Grimm, 1993; Jordan \& Barro, 1995; Barro, Jordan \& Roberts, 1998). This accelerates initial insertion, intensifies participation, systematically develops objective listening and observation, and develops self-awareness in relation to attitudes to cultural difference. Students are sensitised to cultural pluralism, and learn to tolerate ambiguity. Provided with a communicative need and purpose from the start of their sojourn, they adopt an ideal role for residence-abroad students, that of the participant observer. A number of related studies have equally addressed the question of how to take the learner beyond the stage of recognising boundaries and differences between cultures to the point where "the outsider begins to become an insider" (Byram, 1989: 21; cf also Baumgratz-Gangl, 1990, 1993; Byram (1988; 1997), Byram et al. (1991), Byram \& Esarte-Sarries (1991), Byram, Morgan \& Colleagues (1994).

\section{Conclusion}

It is taken for granted, no doubt too easily, that residence abroad will lead to greater proficiency for the individual learner. Many in Europe are more concerned with ideological issues or with enhancing the full range of benefits of residence abroad than with investigating aspects of second language acquisition. For European students, residence abroad is a complex experience with many overlapping objectives: linguistic ones certainly, but equally cultural, academic, personal and professional ones. Research into residence abroad must equally embrace complexity, as an attempt (Coleman, 1998b) to include all relevant variables in a single diagrammatic model shows. To limit residence abroad research to the linguistic outcomes is to distort the experience. Language skills are not merely mechanical: sociocultural and intercultural competence are essential elements of the true linguistic proficiency which residence abroad is expected to enhance. At the same time, without intercultural competence students cannot adopt the attitudes, strategies and behaviours in their interactions with L2landers which alone will enhance their language learning. Intercultural competence is thus both the outcome and the essential prerequisite of student residence abroad. 


\section{References}

Alderson, J. C. \& R. Crawshaw. (1990). Language Needs and Language Preparedness of ERASMUS Students. Unpublished paper, University of Lancaster.

Aldridge, E.-M. 1995. Séjour en primaire. The Year Abroad eds. G. Parker \& A. Rouxeville, 167-176. London: AFLS/CILT.

Allison, M. \& M.-A. Hintze. 1995. Preparing for the Year Abroad: bain de langue ou bain de vie? The Year Abroad eds. G. Parker \& A. Rouxeville, 91-109. London: AFLS/CILT.

Barro, A. \& Grimm, H. 1993. Integrating Language Learning and Cultural Studies: An ethnographic approach to the year abroad. Integrating New Approaches: The Teaching of French in Higher Education eds. J.A. Coleman \& A. Rouxeville, 147-164. London: AFLS/CILT.

Barro, A., S. Jordan \& C. Roberts. 1998. Cultural Practice in Everyday Life: the language learner as ethnographer. Language Learning in Intercultural Perspective ed. M. Byram \& M. Fleming, 76-97. Cambridge: Cambridge University Press.

Batardière, M.-T. 1993. Research Study on Affective and Environmental Factors of Older Learners during Second Language Immersion. Teanga 13: 41-53.

Baumgratz-Gangl, G. 1990. Mobility of Students in Europe. Linguistic and Socio-Cultural Conditions. Luxembourg: Office for Official Publications of the European Communities.

Baumgratz-Gangl, G. (1993). Compétence transculturelle et échanges éducatifs. Paris: Hachette.

Berger, C. 1997. Des lycéens et l'anglais. Représentations sociales d'une langue étrangère. Sens et valeur formatrice d'une discipline. Thèse de doctorat, Université de Paris XIII.

Byram, M. 1988. A Year in France. Durham: University of Durham.

Byram, M. 1989. Cultural Studies in Foreign Language Education. Clevedon/Philadelphia/ Adelaide: Multilingual Matters.

Byram, M. (ed.). 1997. Face to Face: Learning "Language-and-Culture" Through Visits and Exchanges. London: CILT.

Byram, M. \& V. Esarte-Sarries. 1991. Investigating Cultural Studies in Foreign Language Teaching. Clevedon/Philadelphia/Adelaide, Multilingual Matters. 
Byram, M., V. Esarte-Sarries \& S. Taylor. 1991. Cultural Studies and Language Learning: a research report. Clevedon/Philadelphia/Adelaide: Multilingual Matters.

Byram, M., C. Morgan \& Colleagues. 1994. Teaching-and-Learning Language-and-Culture. Clevedon/Philadelphia/Adelaide: Multilingual Matters.

Byram, M. \& G. Zarate, G. (eds.). 1997. The Sociocultural and Intercultural Dimension of Language Learning and Teaching. Strasbourg: Council of Europe.

Byram, M., G. Zarate, \& G. Neuner. 1997. Sociocultural Competence in Language Learning and Teaching. Strasbourg: Council of Europe.

Cain, A. 1990. French Secondary School Students' Perceptions of Foreign Cultures. Language Learning Journal, September: 48-52.

Chambers, G. 1994. A Snapshot in Motivation at 10+, 13+ and 16+. Language Learning Journal 9: 14-18.

Coleman, J.A. 1995. The Current State of Knowledge Concerning Student Residence Abroad. The Year Abroad eds. G. Parker \& A. Rouxeville, 17-42. London: AFLS/CILT.

Coleman, J.A. 1996a. Studying Languages: a survey of British and European students. The proficiency, background, attitudes and motivations of students of foreign languages in the United Kingdom and Europe. London: CILT.

Coleman, J.A. 1996b. A Comparative Study of the Proficiency and Progress of Language Learners in British Universities. Der C-Test. Theoretische Grundlagen und praktische Anwendungen Vol.3, ed. by R. Grotjahn, 367-399. Bochum: Brockmeyer.

Coleman, J.A. 1997. Residence Abroad within Language Study. Language Teaching 30, 1: 1-20.

Coleman, J.A. 1998a. Evolving Intercultural Perceptions Among University Language Learners in Europe. Language Learning in Intercultural Perspective eds. M. Byram \& M. Fleming, 45-75. Cambridge: Cambridge University Press.

Coleman, J.A. 1998b. Student Preparation for Residence Abroad: Two stages in acquiring cross-cultural capability. Cross-Cultural Capability: the Why, the Ways, the Means - New Theories and Methodologies in Language Education, Proceedings of the Conference beld at Leeds Metropolitan University, 15-16 December 1997, eds. D. Killick \& M. Parry, 32-44. Leeds: Leeds Metropolitan University. 
Convey, F. 1995 The Stay Abroad: Objectives, Strategies, Outcomes. The Year Abroad eds. G. Parker \& A. Rouxeville, 127-152. London: AFLS/CILT.

Cormeraie, S. 1995. Cross-Cultural Training: Perceptions and personal Growth. The Year Abroad eds. G. Parker \& A. Rouxeville, 61-75. London: AFLS/CILT.

Dueñas-Tancred, M. \& I. Weber-Newth. 1995. Profiling and Accrediting the Year Abroad. The Year Abroad eds. G. Parker \& A. Rouxeville, 110-126. London: AFLS/CILT.

Dyson, P. (1988). The Effect on Linguistic Competence of the Year Spent Abroad by Students Studying French, German and Spanish at Degree Level. Oxford: Oxford University Language Teaching Centre.

Freed, B. 1995. What Makes Us Think that Students Who Study Abroad Become Fluent? Second Language Acquisition in a Study Abroad Context ed. by B.F. Freed, 123-148. Amsterdam/Philadelphia: John Benjamin.

Gomes Da Costa, B., T.M.F. Smith \& D. Whitely. (1975). German Language Attainment: A Sample Survey of Universities and Colleges in the UK. Heidelberg: Julius Groos Verlag.

Harper, J. E. T., \& S. Cormeraie. 1995. Mergers, Marriages and After: how can training help? Journal of European Industrial Training 19, 1: 24-9.

HEFCE. 1996. Subject overview reports, Quality Assessment of French (2/96), German and related languages (3/96), Iberian languages and studies (4/96), Italian (5/96), Russian and Eastern European languages and studies (7/96). Bristol: Higher Education Funding Council for England.

HMI (Her Majesty's Inspectorate). 1989. Modern Languages in Polytechnics and Colleges: A Survey of Good Practice.

Holec, H. 1994. Self-Directed Learning: an alternative form of training. Strasbourg: Council of Europe.

Inkster, G. 1993. Integrating the Year Abroad. Integrating New Approaches: The Teaching of French in Higher Education eds. J.A. Coleman \& A. Rouxeville, 133-145. London: AFLS/CILT.

Jamieson, D. 1995. Preparation for Assistantship in France: Student-led Interactive Multimedia Projects. The Year Abroad eds. G. Parker \& A. Rouxeville, 177-193. London: AFLS/CILT.

Jordan, S. \& A. Barro. 1995. The Effect of Ethnographic Training on the Year Abroad. The Year Abroad eds. G. Parker \& A. Rouxeville, 76-90. 
London: AFLS/CILT.

Kennedy, F. \& K. Schröder. 1992. Foreign Language Learning Experience, Foreign Language Learning Motivation and European Multilingualism. An Irish approach, with reference to findings in the Netherlands and the United Kingdom. Die Neueren Sprachen 91: 434-52.

Kloss, G. \& U. Zemke. 1987. Foreign Language Competence and Cultural Awareness: Students in European Higher Education Exchanges and Work Placements, U.K. Study. Manchester: University of Manchester Centre for European Studies.

Laudet, C. 1993. Oral Performance of ERASMUS Students: an assessment. Teanga 13,: 13-28.

Lennon, P. 1990a. Investigating Fluency in EFL: A Quantitative Approach. Language Learning 40, 3: 387-417.

Lennon, P. 1990b. The Advanced Learner at Large in the L2 Community: Developments in Spoken Performance. IRAL 28, 4: 309-324.

Lennon, P. 1995. Assessing Short-term Change in Advanced Oral proficiency: Problems of Reliability and Validity in Four Case Studies. ITL Review of Applied Linguistics 109-110: 75-109.

Lillie, E. 1994. Abroad Alone? Student Experience on Study Placements in Continental Europe. Paper presented to Society for Research in Higher Education conference, University of York, December 1994.

Little, D. 1994. Strategic Competence Considered in Relation to Strategic Control of the Language Learning Process. Strasbourg: Council of Europe.

Mauranen, A., \& R. Markkanen. 1994. Students Abroad: Aspects of Exchange Students' Language. Finlance 13: i-vii..

Meara, P. 1994 The Year Abroad and its Effects. Language Learning Journal 10: 32-38.

Milton, J. \& P. Meara. 1995. How Periods Abroad Affect Vocabulary Growth in a Foreign Language. ITL Review of Applied Linguistics 107108:17-34.

Möhle, D., \& M. Raupach. 1983. Planen in der Fremdsprache. Frankfurt: Peter Lang.

Möhle, D. 1984. A Comparison of the Second Language Speech Production of Different Native Speakers. Second Language Productions eds. H.-W. Dechert, D. Möhle \& M. Raupach. Tübingen: Günter Narr.

Morgan, C. 1993. Attitude Change and Foreign Language Culture Learning. Language Teaching 26, 2: 63-75. 
Murphy-Lejeune, E. The Student Strangers: Aspects of Cross-Cultural Adaptation in the Case of International Students. Some Preliminary Findings. The Year Abroad eds. G. Parker \& A. Rouxeville, 43-60. London: AFLS/CILT.

Noreiko, S. 1995 The Year Abroad: Questions of Evaluation. The Year Abroad eds. G. Parker \& A. Rouxeville, 194-207. London: AFLS/CILT. Opper, S., U. Teichler, \& J. Carlson (eds.). 1990. Impact of Study Abroad Programmes on Students and Graduates. London: Jessica Kingsley.

Parker, G. \& A. Rouxeville (eds.). 1995a. The Year Abroad: preparation, monitoring, evaluation, current research and development. London: AFLS/CILT.

Parker, G. \& A. Rouxeville. 1995b. Abroad in Foreign Lands: Theories and Practices. The Year Abroad eds. G. Parker \& A. Rouxeville, 9-16. London: AFLS/CILT.

Raffaldini, T. 1987. Attrition of Communicative Ability among Former Year Abroad Students of French. PhD thesis, Indiana University.

Raupach, M. (1987). Procedural Learning in Advanced Learners of a Foreign Language. The Advanced Language Learner eds. J.A. Coleman \& R. Towell, 123-55. London: CILT.

Regan, V. 1995. The Acquisition of Sociolinguistic Native Speech Norms: effects of a year abroad on L2 learners of French. Second Language Acquisition in a Study Abroad Context ed. B.F. Freed, 245-67. Amsterdam/Philadelphia: John Benjamins.

Rider, M. 1995. The Structured Study Visit: An Alternative to the Year Abroad in a Three Year Degree. The Year Abroad eds. G. Parker \& A. Rouxeville, 153-166. London: AFLS/CILT.

Roberts, C. 1997. The Year Abroad as an Ethnographic Experience. Face to face: learning "language-and-culture" through visits and exchanges ed. M. Byram, 62-76. London: CILT.

Schröder, K. \& K. Macht. 1983. Wieviele Sprachen für Europa? Fremdsprachen-unterricht, Fremdsprachenlernen und europäische Sprachenvielfalt im Urteil von Studierenden des Grundstudiums in Deutschland, Belgien und Finnland. Augsburg: Universität Augsburg (Augsburger I und I Schriften, Band 24).

Sercu, L. (ed.). 1995. Intercultural Competence. A New Challenge for Language Teachers and Trainers in Europe. Aalborg: Aalborg Univesity Press.

Singleton, D. \& E. Singleton. 1992. University-level Learners of Spanish in 
Ireland. Dublin: Trinity College Dublin (Centre for Language and Comnmunication Studies Occasional Paper No. 35).

Teichler, U. 1997. The ERASMUS Experience. Major findings of the ERASMUS evaluation research. Luxembourg: Office for Official Publications of the European Communities.

Towell, R. 1994. The Growth of Linguistic Knowledge and Language processing in Advanced Language Learning. Applied Linguistics and Language Teaching eds. G. Doble \& P. Fawcett, 1-25. Bradford: Department of Modern Languages, University of Bradford (Bradford Occasional Papers no.13).

Towell, R. 1995. Development of Fluency During the Year Abroad. Paper presented to the annual conference of the Society for French Studies, University of Hull, April 1995.

Towell, R., R. Hawkins \& N. Bazergui. 1996. The Development of Fluency in Advanced Learners of French. Applied Linguistics 17, 1: 84119.

Walsh, R. 1994. The Year Abroad - A Linguistic Challenge. Teanga 14: 48-57.

Willis, F.M., G. Doble, U. Sankarayya \& A. Smithers. (1977). Residence Abroad and the Student of Modern Languages: a preliminary survey. Bradford: University of Bradford, Modern Languages Centre. 